\title{
Geographical inequalities in health in New Zealand, 1980-2001: the gap widens
}

\author{
Jamie Pearce
}

Department of Geography, University of Canterbury, New Zealand

\author{
Danny Dorling, Ben Wheeler \\ Department of Geography, University of Sheffield, United Kingdom
}

\author{
Ross Barnett \\ Department of Geography, University of Canterbury, New Zealand
}

\section{Jan Rigby}

Department of Geography, University of Sheffield, United Kingdom

$\mathbf{R}$ ecent studies have noted that, similar to most other Organisation for Economic Cooperation and Development (OECD) countries, mortality rates in New Zealand continue to decrease each year. Between 1980-82 and 200002, life expectancy in New Zealand has increased from 70.4 to 76.3 for males and 76.4 to 81.1 for females. ${ }^{1}$ However, while these improvements in the nation's health are to be welcomed, it is not clear whether equal progress has been made in all areas of the country. Previous studies have noted significant variations in health between different socio-economic groups within the country, which had tended to increase over the past 20 years. ${ }^{2-4}$ In particular, the work by Blakely and colleagues has shown, using linked Census-mortality records, that relative inequalities in mortality increased in the 1980s and 1990s. ${ }^{5,6}$ Furthermore, wide regional variations in health have been noted in New Zealand, including mortality, ${ }^{7}$ cancer incidence and health-related behaviours such as smoking. ${ }^{10,11}$ However, despite the clear regional patterning to the health of New Zealanders, there has been little work done to monitor how the geographical trends in health have evolved over time. ${ }^{4}$ In view of this gap, this paper examines whether geographical inequalities in health in New Zealand have risen during the period 1980 to 2001.

This issue is important because, with the reduction of inequalities at the top of the New Zealand Government's health agenda, ${ }^{12}$ there is a need to monitor the trend in spatial as well as social inequalities over time and to assess the success, or otherwise, of government strategies for reducing health inequalities. In fact, spatial inequalities often reflect social inequalities not well measured by deprivation indices and social inequalities can partly be inequalities for which geographical factors are an underlying cause. ${ }^{13,14}$ Monitoring is necessary because, as has been shown in other countries, without the appropriate supporting social and economic policies, prioritising the reduction in health inequalities may have only limited success in addressing the issue and mortality differentials can continue to worsen. For example, in the United Kingdom (UK) it has been demonstrated that inequalities between rich and poor areas of Britain widened during the 1980s and 1990s and have continued to widen in the early part of the 21 st century, despite the Labour Government's rhetoric about reducing the health divide. ${ }^{15}$

Previous work in New Zealand has noted

\begin{abstract}
Objective: To monitor geographical inequalities in health in New Zealand during the period 1980 to 2001, a time of rapid social and economic change in society.
\end{abstract}

Methods: Age-standardised mortality rates were calculated using mortality records aggregated to a consistent set of geographical areas (the 2001 District Health Boards) for the periods 1980-82, 1985-87, 1990-92, 1995-97 and 19992001. In addition, the Relative Index of Inequality (RII) was calculated for each period to provide a robust measure of mortality rates over time.

Results: Although overall mortality rates have declined through the period 1980 to 2001, the reduction has not been consistent for all areas of New Zealand. Indeed for a small number of DHBs, mortality rates have increased slightly. There has been an increase in the geographical inequalities in health as measured by the RII between each time period except for between 1986 and 1991 , where there was a small reduction.

Conclusions: At the start of the 21st century, geographical inequalities in health in New Zealand have reached very high levels and continue to increase. The excess mortality for the worst areas in New Zealand increased from $15 \%$ in 1981 to $25 \%$ in 2000 . If policy makers are committed to reducing health inequalities then more redistributive economic policies are required.

(Aust N Z J Public Health 2006; 30: 461-6)

\section{Correspondence to:}

Dr Jamie Pearce, Department of Geography, University of Canterbury, Private Bag 4800,

Christchurch 8020, New Zealand. Fax: +64 3364 2907; e-mail: jamie.pearce@canterbury.ac.nz
Submitted: June 2005

Revision requested: September 2005

Accepted: July 2006 
distinct socio-economic gradients in health between different groups of the population. As in other countries, better health tends to be enjoyed by the rich, highly educated and employed and worse health suffered among the poor, less educated, unemployed and the socially disadvantaged. ${ }^{2}$ The rapidly shifting economic and social climate in New Zealand during the 1980s and 1990s has focused attention among health researchers on the evolving health differentials during that period. Since the early 1980s there has been a significant shift in governmental support for New Zealand's welfare state as successive governments have adopted a more neo-liberal policy agenda, which has eroded the long-accepted assumptions of a universal and freely accessible public health system. ${ }^{16}$ These changes have led some commentators to claim that the reforms in New Zealand resulted in social and economic changes that were both more extreme and more rapid than in any other OECD country. ${ }^{17}$ By 2005, socio-economic restructuring has left New Zealand as a very unequal place to live and grow up in with, for example, the unenviable claim of having the fourth highest child poverty rate of the 24 OECD countries. ${ }^{18}$

The health effects of the rapid social and economic restructuring of the 1980s and 1990s has led several researchers to examine the social polarisation in health during this period. ${ }^{10}$ For example, recent studies of Census-mortality cohorts in New Zealand have noted that while mortality rates have fallen for the country as a whole, the gains were greater among those on high incomes. ${ }^{5}$ These results are supported by a separate study that found growing

\section{Table 1: The percentage of the resident population of each District Health Board who were among the most deprived $30 \%$ of all New Zealand residents (2001 NZDep deciles 8, 9 and 10).}

\begin{tabular}{lrrrr}
\hline $\begin{array}{l}\text { District } \\
\text { Health } \\
\text { Board }\end{array}$ & $\begin{array}{c}\text { NZDep } \\
\text { Dec 8 }\end{array}$ & $\begin{array}{c}\text { NZDep } \\
\text { Dec } 9\end{array}$ & $\begin{array}{c}\text { NZDep } \\
\text { Dec 10 }\end{array}$ & $\begin{array}{c}\text { Total } \\
\text { NZDep } \\
8-10\end{array}$ \\
\hline Auckland & 9.9 & 9.4 & 11.0 & 30.3 \\
\hline Bay of Plenty & 10.2 & 13.5 & 13.5 & 37.2 \\
\hline Canterbury & 9.1 & 6.9 & 3.4 & 19.4 \\
\hline Capital and Coast & 6.0 & 4.5 & 9.1 & 19.6 \\
\hline Counties Manukau & 9.0 & 14.2 & 21.2 & 44.4 \\
\hline Hawke's Bay & 10.6 & 11.3 & 15.7 & 37.6 \\
\hline Hutt & 8.1 & 9.0 & 9.9 & 27.0 \\
\hline Lakes & 11.6 & 14.8 & 17.3 & 43.7 \\
\hline Mid Central & 12.5 & 12.3 & 7.4 & 32.2 \\
\hline Nelson-Marlborough & 10.2 & 6.4 & 1.1 & 17.7 \\
\hline Northland & 12.4 & 14.2 & 21.9 & 48.5 \\
\hline Otago & 9.5 & 9.5 & 4.0 & 23.0 \\
\hline South Canterbury & 10.7 & 7.0 & 1.9 & 19.6 \\
\hline Southland & 9.2 & 8.7 & 3.6 & 21.5 \\
\hline Tairawhiti & 11.6 & 17.4 & 30.1 & 59.1 \\
\hline Taranaki & 11.8 & 10.2 & 7.6 & 29.6 \\
\hline Waikato & 11.1 & 12.7 & 11.7 & 35.5 \\
\hline Wairarapa & 10.1 & 9.9 & 4.8 & 24.8 \\
\hline Waitemata & 8.4 & 6.1 & 2.3 & 16.8 \\
\hline West Coast & 20.0 & 11.0 & 6.3 & 37.3 \\
\hline Whanganui & 12.0 & 14.4 & 17.3 & 43.7 \\
\hline & & & & \\
\hline
\end{tabular}

social class differentials in mortality between 1975-77 and 199597 in New Zealand ${ }^{19}$ and other work that found a polarisation in measures such as health expectancy during the past 20 years..$^{20}$ However, variations in mortality are not limited to differences between socio-economic groups but also differences between ethnic groups in New Zealand. For example, it has been noted that there is a gap in life expectancy of 10.8 years for Maori and 7.7 years for Pacific people compared with non-Maori non-Pacific people, a gap which has grown over the past 20 years. ${ }^{6}$

Despite the attention paid to the socio-economic and ethnic disparities in health in New Zealand, little consideration has been given to regional differences in health. This contrasts with the attention given elsewhere to geographical differences in health by researchers ${ }^{21}$ and by policy makers focusing on strategies to reduce health inequalities. ${ }^{22}$ The lack of consideration given to geographical differences in health in New Zealand is perhaps surprising given the plethora of international studies that have noted the role of contextual factors or place-based effects in explaining health outcomes. ${ }^{23}$ One of the few geographical studies of mortality in New Zealand found distinct regional trends; higher life expectancy in the regional council areas with a significant urban population (e.g. Auckland and Wellington) and lower life expectancies in more sparsely populated regions (such as Gisborne). ${ }^{1}$ Similarly, using small area measures of deprivation it has been noted that the difference in life expectancy between the least and most deprived areas of New Zealand is approximately nine years for males and seven years for females. ${ }^{24}$ However, most previous studies have only considered one point in time and insufficient attention has been given to assessing possible spatial polarisation in mortality during the 1980 s and 1990s.

\section{Methods}

Mortality records were extracted for the period 1980 to 2001 from the New Zealand Health Information Service (NZHIS) Mortality Collection. For each year, the mortality data were configured to the 21 District Health Boards (DHBs) across the country using consistent geographical units (2001 boundaries). The DHBs were formed in 2001 and are responsible for the provision of health and disability services in their region. The boards have an average population of 194,000 and range from 31,000 to $489,000{ }^{25}$ The small number of unspecified and overseas deaths $(0.45 \%$ of total deaths) were excluded from the analysis.

Directly age/sex standardised mortality rates (ASRs) were calculated for each DHB for the periods 1980-82, 1985-87, 1990-92, 1995-97 and 1999-2001 (mortality data for 2002 were not available at the time of study), using the total contemporary New Zealand population as the standard. For each time period, the total population for each age-sex group (e.g. 1980, 1981 and 1982) was used as the denominator. Age- and sex-specific population data for 36 groups (males and females 0-4, 5-9, 1014 up to 85+) were supplied from the five Censuses that took place during this period. For inter-Census years, population estimates were calculated for each age-sex group through linear interpolation. For comparison, DHB ASRs were also calculated 
using the World Health Organization (WHO) year 2000 population as the standard.

In addition, the Relative Index of Inequality (RII) was calculated by ranking areas by poverty in 2001 weighted by the total population in $2001 .{ }^{26}$ The metric provides an easily interpretable measure of the socio-economic gap in mortality between the DHBs across New Zealand. The poverty measure used was the percentage of the resident population of each DHB who were among the most deprived $30 \%$ of all residents (2001 NZDep deciles 8, 9 and 10) (see Table 1). The first three deciles were combined because in international studies relative poverty often equates to roughly the poorest third of the population. The RII provides a consistent measure of health inequalities across a population because it incorporates the mortality rates of all DHBs rather than comparing, say, just those areas with the highest and lowest mortality rates. The index provides a measure of the extent of inequalities that can be best summarised as the averaged difference between the poorest and least poor in society. Furthermore, the RII is less sensitive to changing definitions of poverty over time, hence the measure allows comparisons between different time periods. ${ }^{27}$ It is also the most appropriate measure for the comparison of rates and ratio $\operatorname{spreads}^{28}$ (see Low and Low for more details ${ }^{26}$ ).

\section{Results}

Although there has been an overall reduction in mortality rates during the period 1980 to 2001, the improvements have not been consistent in all areas of New Zealand. Most DHBs in New Zealand have experienced a reduction in their ASRs between 1980 and 2001 but in some areas the improvement is at best only moderate and in fact for some DHBs, mortality rates have increased (see Table 2).
For example, while the West Coast DHB has experienced a large drop in (age/sex directly standardised) mortality from 1,178 to 813 per 100,000 people during the study period, other DHBs such as Whanganui have actually witnessed a small increase in mortality (from 801 to 828 per 100,000). These results are slightly sensitive to the reference population used to calculate the ASRs as small differences were found when the WHO standard population was used instead of the New Zealand standard population. However, the general conclusions are not affected.

Given the geographically uneven changes in mortality rates across New Zealand, it is perhaps not surprising that there has been an overall increase in the Relative Index of Inequality (RII) between 1980 and 2001 (see Figure 1). The RII incorporates the mortality rates of all DHBs rather than comparing, say, just those areas with the highest and lowest mortality, but does, in effect, produce a comparison between the hypothetical extremes. Using contemporary New Zealand data for standardisation, between 1980 and 2001 the RII increased from 1.15 to 1.25. In other words, the mortality risk of the poorest DHB compared with the richest DHB was 1.15 times greater in 1980 but the risk increased to 1.25 by 2001. The results therefore show that the level of health inequalities in New Zealand equates to an increase in excess mortality, for the worst off areas, from $15 \%$ in 1981 to $25 \%$ by 2000 . The method of standardisation has very little effect on the RII, with direct and indirect methods yielding almost identical results. Very similar results are also obtained using a single, external standard population for each time period (the WHO world population), with the RII increasing from 1.17 to 1.31 if that age/sex standard profile is used in standardisation.

With regard to the RII figures resulting from nationally

Table 2: Geographical inequality in mortality in New Zealand, 1980-2001. Age-standardised rates per 100,000 people for District Health Boards (2001 boundaries).

\begin{tabular}{|c|c|c|c|c|c|c|}
\hline District Health Board & $1980-82$ & $1985-87$ & $1990-92$ & $1995-97$ & $1999-2001$ & $\begin{array}{c}\text { Ratio 99-01: } \\
80-82 \\
\end{array}$ \\
\hline Northland & 824 & 845 & 813 & 833 & 798 & 0.97 \\
\hline Waitemata & 704 & 721 & 700 & 705 & 658 & 0.93 \\
\hline Auckland & 835 & 878 & 788 & 774 & 713 & 0.85 \\
\hline Counties Manukau & 820 & 838 & 787 & 766 & 744 & 0.91 \\
\hline Waikato & 818 & 815 & 781 & 761 & 768 & 0.94 \\
\hline Lakes & 844 & 931 & 857 & 868 & 863 & 1.02 \\
\hline Bay of Plenty & 790 & 814 & 776 & 765 & 747 & 0.95 \\
\hline Tairawhiti & 940 & 906 & 860 & 983 & 946 & 1.01 \\
\hline Taranaki & 817 & 851 & 796 & 730 & 757 & 0.93 \\
\hline Hawke's Bay & 835 & 873 & 829 & 801 & 802 & 0.96 \\
\hline Whanganui & 801 & 816 & 799 & 765 & 828 & 1.03 \\
\hline Mid Central & 861 & 910 & 846 & 825 & 793 & 0.92 \\
\hline Hutt Valley & 826 & 867 & 804 & 827 & 777 & 0.94 \\
\hline Capital and Coast & 806 & 797 & 765 & 744 & 711 & 0.88 \\
\hline Wairarapa & 868 & 835 & 874 & 813 & 763 & 0.88 \\
\hline Nelson-Marlborough & 761 & 715 & 665 & 702 & 702 & 0.92 \\
\hline West Coast & 1,178 & 1,211 & 1,065 & 1,105 & 813 & 0.69 \\
\hline Canterbury & 791 & 801 & 771 & 745 & 694 & 0.88 \\
\hline South Canterbury & 855 & 840 & 797 & 778 & 744 & 0.87 \\
\hline Otago & 848 & 856 & 805 & 758 & 748 & 0.88 \\
\hline Southland & 878 & 919 & 872 & 835 & 793 & 0.90 \\
\hline RII & 1.15 & 1.20 & 1.17 & 1.24 & 1.25 & \\
\hline
\end{tabular}


standardised methods, it is interesting to note that following an increase in the RII between 1981 and 1986, there was a temporary reduction between 1986 and 1991 that preceded a substantial increase in the early to mid 1990s. Between 1996 and 2000, there was a small increase in the RII from 1.24 to 1.25 . The externally standardised RII trend follows a similar pattern, although there is only a slowing of the rate of increase rather than a decline in the late 1980s.

\section{Discussion}

This paper has examined whether mortality in New Zealand has become more geographically polarised during the 1980s and 1990s, a period of rapid social and economic change. The results demonstrate that although mortality rates in New Zealand have decreased for the nation as a whole between 1980 and 2001, the improvements have not been equal across all areas of New Zealand. Some regions of the country have experienced improvements in health that were substantially better than other regions, which has resulted in rising geographical inequalities in health. The greatest improvements have been in the West Coast, Auckland and South Canterbury DHBs, whereas in Whanganui, Lakes and Tairawhiti the DHB mortality rates have actually worsened during the study period. The overall increase in inequality in mortality between 1980 and 2001 has not been consistent throughout the period because, while there was a reduction in geographical inequality in the mid to late 1980s, this decrease was followed by a sharp rise in the early 1990s.

The slightly different trend in RII for the late 1980s using the WHO standard population may be explained by a larger ageing population in New Zealand compared with the world standard, coupled with a sharp decline in the mortality rate among older New Zealanders between 1985-87 and 1990-92. Inequalities tend to be greater in absolute (if not relative) terms among older age groups here (and these inequalities strongly influence the overall ratios). The influence that using a global population structure has on accentuating the 'younger' WHO standard population de-emphasises the effect of the decline in death rates among the older population while the New Zealand standard population does not. The RII trend based on external standardisation therefore does not decline as much as the RII derived from domestic standardisation, which is more strongly influenced by declining mortality among the older age groups. Furthermore, the use of the contemporary New Zealand population is strongly influenced by changing patterns of immigration and emigration by age and sex over time, but it should be noted that despite using two very different standard populations the overall results of our study only alter slightly with a small effect in the middle of our study period. The general conclusions are not affected.

The results are consistent with other studies, which have noted a polarisation in mortality between different social groups in New Zealand. For example, Blakely et al. ${ }^{5}$ noted an increase in relative inequality for all-cause mortality between high and low income groups during the 1980s and 1990s. These results were supported by the work of Davis et al. ${ }^{20}$ who found increasing health differentials over the 1980s, and those of Tobias et al., ${ }^{24}$ who found levels of geographical inequality in life expectancy that remained at a stable but very high level in the late 1990s. Similarly, growing social class differentials in premature mortality have been noted between the mid 1970s and mid 1990s. ${ }^{19}$ However, none of these studies examine the geographical widening of mortality, which has been the focus of this study. The results of this study are also consistent with research in other countries, which has noted rising geographical inequalities in health during the 1980s and 1990s in the UK, ${ }^{29}$ western Europe ${ }^{30}$ and Australia. ${ }^{31}$ For example, it has been shown that geographical inequalities in health between rich and poor areas of the UK have continued to polarise throughout

Figure 1: Relative Index of Inequality (mortality) in New Zealand, 1980 to 2001.

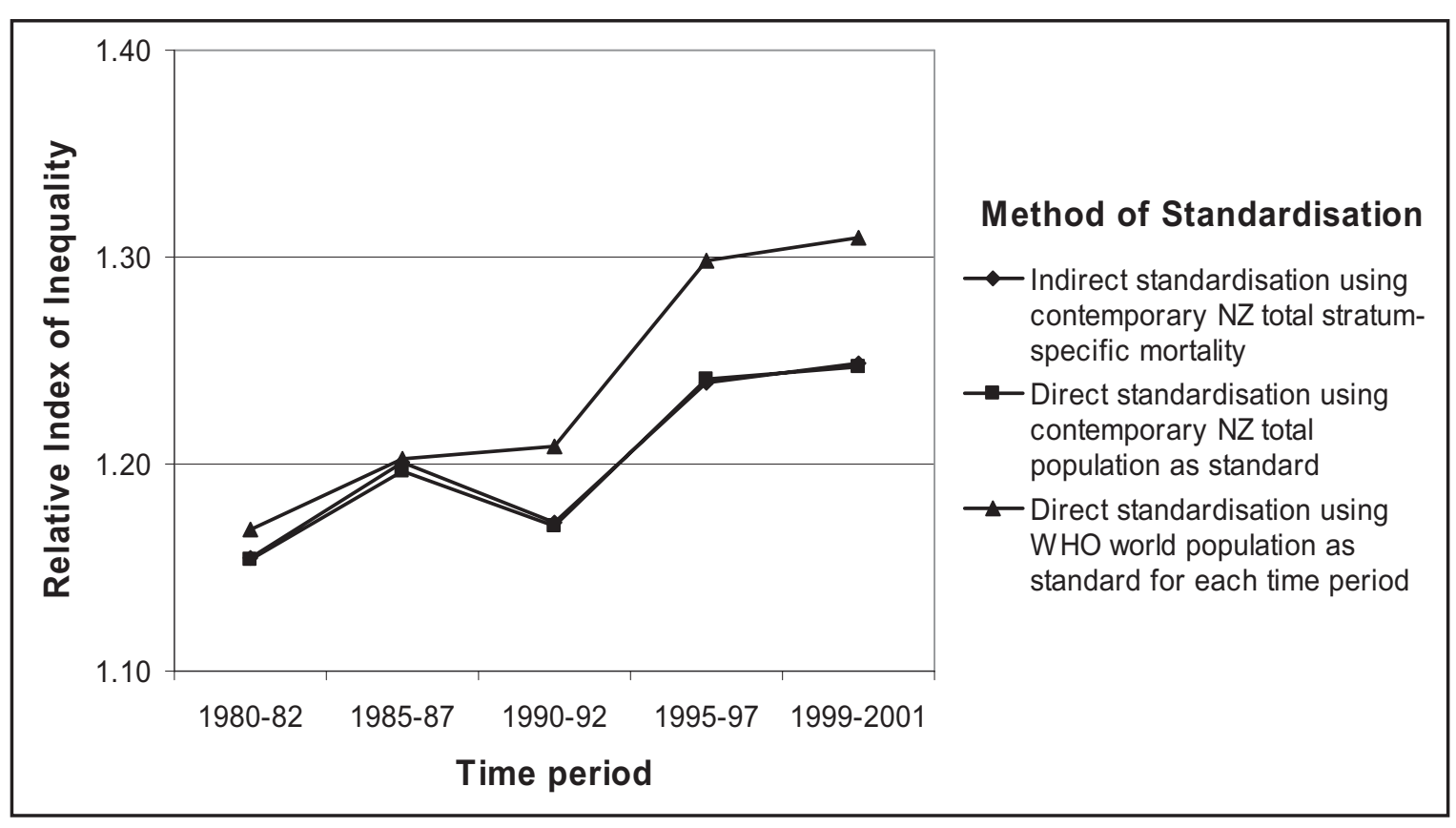


the 1980 s, 1990 s and into the start of the 21 st century. ${ }^{15}$

However, while the geographical polarisation of health outcomes is increasingly common, understanding the causes of such trends is more difficult. Although there are many possible explanations for such trends, we will discuss four strong contenders that also incorporate aspects of many other possibilities: the effects of increased income inequality; increasing ethnic differentials in health; selective patterns of migration; and variations in access to health services.

The increase in geographical differences in mortality rates closely mirrors other studies, which have reported changes in income inequalities both at the individual/household ${ }^{32}$ as well as at the regional level. ${ }^{33}$ Fluctuations in the pattern of income inequality during the 1980s and 1990s then seem to be followed, with a short lag, by the trend in health inequalities. However, the reasons for this link are not entirely clear. Such trends could simply reflect compositional effects in the form of greater differences between regions in the concentration of poorer households. Alternatively, they could be indicative of contextual effects associated with greater income inequality within DHBs. However, evidence supporting the effects of 'income inequality' on health is mixed. ${ }^{34,35}$ While this is also true of New Zealand, ${ }^{36}$ there is some limited evidence that high levels of community ethnic inequality, independent of absolute deprivation, lead to poorer health outcomes. ${ }^{10}$ It is, however, important to remember that a recent review of 169 published studies on the relationship between income inequality and health found overwhelming evidence that average standards of health tend to be better in rich countries where income inequalities are lower. ${ }^{35}$

Second, it is feasible that the growing geographical inequalities may partially be explained by changing ethnic disparities in health between Maori and non-Maori New Zealanders during the 1980s and 1990s ${ }^{56}$ However, although there are significant and increasing ethnic differentials in health in New Zealand, the changes are not likely to be sufficient to account for the widening geographical differentials noted in this study. Maori deaths only account for approximately $10-15 \%$ of the total deaths in New Zealand ${ }^{37}$ and hence the ethnic differences in mortality are unlikely to account for the substantial increase in the geographical differentials. This interpretation is supported by a large body of evidence from the United States and United Kingdom, which suggests that ethnic inequalities in health are principally an outcome of socioeconomic differentials. ${ }^{38}$ Instead, the widening geographical health differentials are likely to reflect greater differences between the 'deprived' and 'prosperous' areas of New Zealand.

Third, growing geographical inequalities in health may be an outcome of selective patterns of migration to and from DHBs during the study period. Previous studies in the UK (a country with high levels of internal migration) have suggested that the different migration patterns of ill people as compared with healthy people may further increase the widening mortality gap. ${ }^{39}$ New Zealand has one of highest proportions of the population born overseas (19.5\% in 2001) among OECD countries ${ }^{40}$ and this high level of immigration tends to result in high levels of population sorting between areas. New Zealand is also unique among affluent nations in having a similarly high level of emigration as immigration, resulting further in a constant re-sorting of people by area within the country because of exits from various parts of the country to overseas and entries of often very different people to often different parts of the country. This unique migration history may help reveal patterns of health influenced by migration more than can easily be revealed in countries with a less dramatic history of near mass exodus and entry as New Zealand has experienced over the course of at least the past half century.

Finally, differential access to health services on the part of particular groups may be a factor in increasing regional differences in mortality rates since the 1980s. Although the recent development of capitated primary health organisations has improved access to care in recent years, ${ }^{41}$ this was not the case during the 1980s and 1990s when substantial co-payments resulted in the under-utilisation of services by at-risk groups. ${ }^{42,43}$ This was a significant trend especially since poor access to primary health care services is the health system factor most likely to be related to poor health outcomes ${ }^{44}$ and increased rates of hospitalisation of the poor. ${ }^{45}$ Moreover, continued rationing of public hospital services has affected some regions more than others ${ }^{46}$ and may well have contributed to emerging disparities in health outcomes. As the health needs in particular areas rise it becomes more and more difficult to provide a similar standard of care in those areas as in other areas as the time of general practitioners and other health professionals is increasingly spent on immediate treatment, leaving less time available for preventive work. An extra few minutes to spend with each patient is time that can be spent fruitfully advising patients about actions they might take to preserve their good health. This is less of a problem when health care is distributed on the basis of need rather than equally irrespective of need.

It should be noted that the four potential explanations for rising spatial inequalities in health in New Zealand are not mutually exclusive. As noted elsewhere, the sharp rise in geographical inequalities in health is likely to be a manifestation of many complex and socially patterned and interrelated factors that operate at a range of scales across the lifecourse. ${ }^{47}$ For example, it has been noted that there have been differential rates of migration between the various ethnic groups in New Zealand during the period 1981$2001 .{ }^{48}$ During the 1990s regional migration intensities (or turnover rate) were typically higher for Maori than for the population as a whole. ${ }^{48}$ Similarly, increasing social and economic inequality and processes of selective migration are also inextricably linked. It has been suggested that as economic inequality increases so the patterns of migration become more selective and over time there are some places to which, increasingly, only the most wealthy have the resources to be able to move to. ${ }^{49}$

The widening geographical disparities in health between areas of New Zealand should be of great concern to policy makers because the results of this study suggest that current policies to address health inequalities in the country are not sufficiently potent. Although an aim to see a reduction in health inequalities is firmly enshrined in the New Zealand Government's health strategy, 
the results demonstrate that there has not been a reduction in health inequalities in New Zealand over the past 20 years. Spatial inequalities in health increased during the 1980s and 1990s and, at the start of this century, are persisting at consistently high levels. These results suggest that government policy has been insufficient to turn the tide in reducing health inequalities by targeting the greatest improvements in health towards the most disadvantaged in New Zealand society. It is not impossible to envisage that future studies might find that certain aspects of government policy have helped influence this trend rather than having had an insignificant effect.

\section{Acknowledgements}

We thank Craig Wright and Li-Chia Yeh from the Public Health Intelligence group at the Ministry of Health for providing the mortality and population data. We would also like to thank three anonymous reviewers for their helpful comments on an earlier draft of this paper.

\section{References}

1. Statistics New Zealand. New Zealand Life Tables, 2000-2002. Wellington (NZ) Government of New Zealand; 2004.

2. Howden-Chapman P, Tobias M, editors. Social Inequalities in Health, New Zealand 1999: A Summary. Wellington (NZ): Ministry of Health; 2000.

3. Ministry of Health. Taking the Pulse: the 1996/97 New Zealand Health Survey. Wellington (NZ): Ministry of Health; 1999.

4. Pearce J, Dorling D. Increasing geographical inequalities in health in New Zealand, 1980-2001. Int J Epidemiol. 2006;35(3):597-603.

5. Blakely T, Fawcett J, Atkinson J, Tobias M, Cheung J. Decades of Disparity II: Socioeconomic Mortality Trends in New Zealand, 1981-1999. Wellington (NZ): Ministry of Health; 2005.

6. Blakely T, Tobias M, Robson B, Ajwani S, Bonne M, Woodward A. Widening ethnic mortality disparities in New Zealand 1981-99. Soc Sci Med. 2005;61(10):2233-51

7. Ministry of Health. Reducing Inequalities in Health. Wellington (NZ): Government of New Zealand; 2002.

8. Ministry of Health. Atlas of Cancer Mortality in New Zealand 1994-2000. Wellington (NZ): Ministry of Health; 2005.

9. Pearce J, Barnett R, Kingham S. Slip! Slap! Slop! Cutaneous malignant melanoma incidence and social status in New Zealand, 1995-2000. Health Place. 2006;12(3):239-52

10. Barnett R, Pearce J, Moon G. Does social inequality matter? Assessing the effects of changing ethnic socio-economic disparities on Maori smoking in New Zealand, 1981-96. Soc Sci Med. 2005;60:1515-26.

11. Moon G, Barnett R. Spatial scale and the geography of tobacco smoking in New Zealand: A multilevel perspective. New Zealand Geographer. 2003;59(2):615 .

12. Ministry of Health. New Zealand Health Strategy. Wellington (NZ): Ministry of Health; 2000.

13. Tunstall HV, Shaw M, Dorling D. Places and health. J Epidemiol Community Health 2004;58(1):6-10.

14. Macintyre S, Maciver S, Sooman A. Area, class and health: should we be focusing on places or people? J Soc Policy. 1993;22(2):213-34.

15. Shaw M, Davey Smith G, Dorling D. Health inequalities and New Labour: how the promises compare with real progress. Br Med J. 2005;330:1016-21.

16. Hornblow A. New Zealand's health reforms: a clash of cultures. Br Med J. 1997;314(7098):1892-4.

17. Nagel J. Social choice in a pluralitarian democracy: the politics of market liberalization in New Zealand. Br J Political Science. 1998;28:223-67.

18. United Nations Children's Fund. Child Poverty in Rich Countries, 2005 Innocenti Report Card No. 6. Florence (IT): UNICEF Innocenti Research Centre; 2005.

19. Pearce N, Davis P, Sporle A. Persistent social class mortality differences in New Zealand men aged 15-64: an analysis of mortality during 1995-97. Aust N Z J Public Health. 2002;26(1):17-22.

20. Davis P, Graham P, Pearce N. Health expectancy in New Zealand, 1981-1991: social variations and trends in a period of rapid social and economic change. J Epidemiol Community Health. 1999;53(9):519-27.
21. Davey Smith G, Dorling D, Mitchell R, Shaw M. Health inequalities in Britain: continuing increases up to the end of the 20th century. J Epidemiol Community Health. 2002;56:434-5.

22. Acheson D. Independent Inquiry into Inequalities in Health. London (UK): Stationery Office; 1998.

23. Duncan C, Jones K, Moon G. Do places matter? A multi-level analysis of regional variation in health-related behaviour in Britain. Soc Sci Med. 1993;37:725-33.

24. Tobias M, Salmond C, Crampton P, Chan M, Marmot M, Reid P. Life Expectancy and Small Area Deprivation. Wellington (NZ): Ministry of Health; 2001.

25. Ministry of Health. Frequently Asked Questions About District Health Boards. Wellington (NZ): Ministry of Health; 2005.

26. Low A, Low A. Measuring the gap: quantifying and comparing local health inequalities. J Public Health. 2004;2(4):388-95.

27. Wagstaff A, Paci P, Doorslaer E. On the measurement of inequalities in health. Soc Sci Med. 1991;33(5):545-57.

28. Shaw M, Davey Smith G, Dorling D. Health inequalities under New Labour: author's reply. Br Med J. 2006;330:1507-8.

29. Shaw M, Dorling D, Gordon D, Davey Smith G. The Widening Gap: Health Inequalities and Policy in Britain. Bristol (UK): Policy Press; 1999.

30. Kunst AE, Bos V, Lahelma E, Bartley M, Lissau I, Regidor E, et al. Trends in socioeconomic inequalities in self-assessed health in 10 European countries. Int J Epidemiol. 2005;34(2):295-305.

31. Hayes L, Quine S, Taylor R, Berry G. Socio-economic mortality differentials in Sydney over a quarter of a century, 1970-94. Aust N Z J Public Health. 2002;26(4):311-7.

32. O'Dea D. The changes in New Zealand's income distribution. In: 2000 Treasury Working Papers. Wellington (NZ): The Treasury; 2006.

33. Martin B. Sub-national Income Differentials 1986-1996. Hamilton (NZ): Population Studies Centre, University of Waikato; 1999.

34. Lynch J, Smith GD, Harper S, Hillemeier M, Ross N, Kaplan GA, et al. Is income inequality a determinant of population health? Part 1 . A systematic review. Milbank Q. 2004;82(1):5-99.

35. Wilkinson RG, Pickett KE. Income inequality and population health: A review and explanation of the evidence. Soc Sci Med. 2006;62(7):1768-84.

36. Blakely T, Atkinson J, O'Dea D. No association of income inequality with adult mortality within New Zealand: A multi-level study of 1.4 million 25-64 year olds. J Epidemiol Community Health. 2003;57(4):279-84.

37. New Zealand Health Information Service. Mortality and Demographic Data 2000. Wellington (NZ): Ministry of Health; 2004.

38. Nazroo JY. The structuring of ethnic inequalities in health: economic position, racial discrimination, and racism. Am J Public Health. 2003;93(2):277-84.

39. Brimblecombe N, Dorling D, Shaw M. Mortality and migration in Britain, first results from the British Household Panel Survey. Soc Sci Med. 1999;49(7):9818 .

40. Organisation for Economic Co-operation and Development. OECD Factbook 2005: Economic, Environmental and Social Statistics. Paris (FR): OECD; 2004.

41. Crampton P, Davis P, Lay-Yee R, Raymont A, Forrest CB, Starfield B. Does community-governed nonprofit primary care improve access to services? Crosssectional survey of practice characteristics. Int J Health Serv. 2005;35(3):46578.

42. Barnett JR, Coyle P, Kearns RA. Holes in the safety net? Assessing the effects of targeted benefits upon the health care utilization of poor New Zealanders. Health Soc Care Community. 2000;8(3):159-71.

43. Barnett R. Coping with the costs of primary care? Household and locational variations in the survival strategies of the urban poor. Health Place. 2001;7(2):141-57.

44. Starfield B, Shi L, Macinko J. Contribution of primary care to health systems and health. Milbank Q. 2005;83(3):457-502.

45. Barnett R, Lauer G. Urban deprivation and public hospital admissions in Christchurch, New Zealand, 1990-1997. Health Soc Care Community. 2003;11(4):299-313.

46. Barnett P, Barnett J. Reform and changes in health service provision. In: Dew K, Davis P, editors. Health and Society in Aotearoa New Zealand. 2nd ed. Auckland (NZ): Oxford University Press; 2005. p. 178-93.

47. Davey Smith G. Health Inequalities: Lifecourse Approaches. Bristol (UK): Policy Press; 2003.

48. Newell J. Internal and international migration in New Zealand's regions, 1986-1996. J Population Research and the New Zealand Population Review [special issue]. 2002;195-217.

49. Pearce J, Dorling D. The place of population change in explaining geographical inequalities in health in New Zealand. Int J Epidemiol. 2006;35(4)10991100 . 